\title{
ALCANCES DE LA DISCRIMINACIÓN RACIAL O ÉTNICA Y SU VINCULACIÓN HISTÓRICA CON LA DISCRIMINACIÓN POR SEXO
}

\author{
NiLDA GARAY MONTAÑEZ \\ Universidad de Alicante
}

Fecha de recepción: 8-10-2008.

Fecha de aceptación: 27-10-2008.

\section{Introducción}

El concepto de igualdad jurídica construido por la tradición liberal en los orígenes del Estado moderno es objeto de crítica de parte de la teoría feminista porque con su formalidad y su falsa universalidad ha excluido a diversos grupos de personas impidiéndoles el disfrute de sus derechos constitucionales. Posteriormente, para salvar estos defectos junto a ella se incorporó la cláusula de prohibición de discriminación. Esta prohibición constituye una manifestación, y posiblemente la más intensa, del principio de igualdad y un instrumento específico para su realización ${ }^{1}$. En la historia del constitucionalismo el concepto «discriminación» fue incorporado a partir del siglo XX tomándose en cuenta su significado peyorativo por llevar en sí una carga de prejuicios con graves consecuencias en el estatus jurídico de las personas. Estos prejuicios han estado presentes en las teorizaciones que sobre igualdad se han hecho en la historiografía occidental, por eso esta igualdad tan elogiada desde el nacimiento del constitucionalismo fue corregida tardíamente con la prohibición de discriminación. La historia sesgada alude a que tras las graves consecuencias de la discriminación racial del colectivo judío durante la Segunda Guerra Mundial, su prohibición fue necesaria. Sin embargo, hay que tener en cuenta

1. RodríGUEZ-PIÑERO, Miguel y FERnÁNDEZ LóPEZ, María Fernanda: Igualdad y discriminación, Madrid, Tecnos, 1986, p. 17. 
que tal discriminación siempre ha existido y ha sido causa de grandes conflictos socio-políticos hasta antes de la Gran Guerra. Hay que subrayar que en las mismas fundamentaciones sobre igualdad siempre se ha apelado a la discriminación de lo otro básicamente por su raza y sexo, por tanto, estas dos formas de discriminación han caminado juntas en la historia del Derecho y, en función de éstas se ha construido todo el edificio jurídico-político llegándose finalmente a maquillarlas y ocultarlas con el velo del constitucionalismo liberal.

En este artículo se ofrecen algunos alcances de la tesis doctoral que se está elaborando sobre discriminación racial $^{2}$ en la que se plantean posibles soluciones a esta problemática (casi similar a la discriminación por sexo) recogiendo las contribuciones del Derecho antidiscriminatorio, especialmente las referidas a la discriminación por sexo, ya que el Derecho antidiscriminatorio dirigido a erradicar la discriminación por sexo (producto de las aportaciones de la teoría feminista) es más inclusivo en la medida que se trata de la materialización de la igualdad de la mitad de la especie humana y no de una minoría. En suma, se formula la necesidad de construir el Derecho contra la discriminación racial a partir del elaborado para luchar contra la discriminación contra las mujeres, siendo por ejemplo ésa la tendencia del Derecho de la Unión Europea ${ }^{3}$.

En este escrito se hace un breve repaso sobre la huella histórica de la discriminación racial resaltando sus similitudes con la discriminación por sexo. Se enfatizará cómo éstas han sostenido todos los modos de producción y todas las formas de organización política sin que hasta la fecha se les haya tomado en serio en la construcción de una sociedad más igualitaria. Desde

2. Se trata del estudio de la discriminación racial del colectivo indígena en Hispanoamérica, en concreto, en el Perú. Lo indígena en el Perú está representado por un colectivo históricamente discriminado por motivo de raza o etnia, en consecuencia, no son considerados «sujeto de derecho» y por tanto no pueden ejercer plenamente sus derechos fundamentales.

3. Se coincide en este aspecto con la posición Rey Martínez. Ver: Rey Martínez, Fernando: «La prohibición de discriminación racial o étnica en la Unión Europea y en España. El caso de la minoría gitana», Revista Bimestral Gitanos, Pensamiento y Cultura, 19, Fundación Secretariado Gitano, Madrid, abril de 2003, <http://www.gitanos.org/revista/ articulos/19a_fondo.htm>, consultado el 14-08-2008. Se ha tomado como referencia el derecho antidiscriminatorio latino en la medida de las similitudes con el derecho hispanoamericano y porque en Europa Continental se está construyendo lo que se hizo al revés en el derecho estadounidense. Los resultados del derecho antidiscriminatorio por raza elaborado allí para erradicar la discriminación contra la población afrodescendiente no han sido positivos y es más, los graves efectos de la discriminación racial están englobando a otros colectivos como el hispano. 
la perspectiva occidental ${ }^{4}$, este repaso partirá desde la Grecia antigua hasta la Ilustración, que es el momento en que se refuerza la teorización sobre el «sujeto de derecho» y que más adelante, tras las revoluciones del siglo XVIII, aparecerá plasmado en las Declaraciones de derechos paradigmáticas, que se supone construyeron una «avanzada» idea de igualdad. La razón por la que se finaliza en esta etapa histórica es porque en el seno del Siglo de las Luces, surgió un planteamiento crítico que exigió la igualdad universal denunciando los defectos de la razón por estar cargada de prejuicios: la teoría feminista. Precisamente ésta propuso desde sus inicios la erradicación de los prejuicios relacionados con dos formas de discriminación muy similares: la racial y por sexo.

\section{Discriminación étnica o racial: Delimitación conceptual}

En el siglo XV el término «raza» no se utilizó, pero entonces, sí que ya se había empezado a relacionar las características biológicas visibles, es decir, el fenotipo de las personas para clasificarlas y excluirlas. «Raza» y su significado aparecen a partir de la segunda mitad del siglo XVIII con los «científicos» de la Ilustración ${ }^{5}$. El término «racismo» se incorpora en el período de entreguerras en el siglo XX. Tan solo después de la segunda Guerra Mundial dicho término se instala definitivamente en el acervo cultural occidental ${ }^{6}$. No obstante la novedad de la noción «científica» de racismo, no sucede lo mismo con el fenómeno como tal, pues éste es mucho más antiguo ${ }^{7}$. Las elites dirigentes han tenido siempre un papel destacado en esta discriminación y en su institucionalización a través de la imposición de creencias basadas en prejuicios llegando incluso a plasmarse en el Derecho. Estos prejuicios por

4. Para la historia hegemónica, Occidente es el punto de partida cuya construcción se inició con el Renacimiento recogiendo mitos elaborados a partir de la Grecia antigua. La historia occidental se fabricó con un eje central: el hombre europeo. Y más adelante, con el triunfo de la razón, la lectura selectiva de la historia occidental hizo desaparecer a Oriente del pensamiento europeo. Por eso el mito de origen de Occidente es exclusivamente Grecorromano, que ha expulsado los orígenes orientales y no cristianos de la civilización europea (BESSIS, Sophie: Occidente y los otros. Historia de una supremacía, Madrid, Alianza, 2001, p. 25), y considero que también se ha ocultado su carácter patriarcal. En el seno de esta «civilización» selectiva y etnocéntrica aparece el constitucionalismo.

5. Para una mejor comprensión se hará alusión al término «raza» al margen de su aparición histórica como categoría «científica».

6. BLÁZQUEZ-RUiz, F. Javier: «Introducción: Genealogía, dinámica y propuestas éticas frente al racismo y xenofobia», en BLÁzQUEZ-RUIZ, F. Javier (Dir.): 10 palabras clave sobre racismo y xenofobia, Navarra, Editorial Verbo Divino, 1996, pp. 32-33.

7. Wieviorka, Michel: El espacio del racismo, Barcelona, Paidos, 1992, p. 27.

Feminismo/s 12, diciembre 2008, pp. 271-298 
ser difusos no suelen tener una frontera definida y su contenido oscila entre lo étnico y lo racial ${ }^{8}$.

Según Wieviorka, la discriminación racial tiene que ver con «la presencia de la idea de un vínculo entre los atributos o el patrimonio -físico, genético o biológico- de un individuo (o de un grupo) y sus caracteres intelectuales y morales $»^{9}$ de modo que justifican relaciones de dominación, exclusión, persecución o destrucción ${ }^{10}$. Por su parte, Rodríguez-Piñero y Fernández López, señalan que el término «raza» «tiene un sentido genérico, elástico e impreciso» ${ }^{11}$, es decir, que la expresión raza en esta forma de discriminación «no se limita sólo al sentido biológico y científico de especies «cerradas» del hombre, con unas variables genéticas diferenciadoras que se reflejan en unas características físicas hereditarias distintas, sino que, como relativo a una discriminación, alude más a grupos diferenciados históricamente» ${ }^{12}$. Ello implica que la discriminación «racial» comprende no sólo diferencias genéticas sino también la procedencia u origen nacional o étnico, el linaje y, a través del nacimiento, el origen o procedencia social ${ }^{13}$. Es decir, que la discriminación racial está relacionada estrechamente con la discriminación étnica. La Convención Internacional sobre la Eliminación de todas formas de Discriminación Racial $^{14}$ utiliza la expresión discriminación racial o étnica para definir toda «distinción, exclusión, restricción o preferencia basada en motivos de raza, color, linaje u origen nacional o étnico que tenga por objeto o por resultado anular o menoscabar el reconocimiento, goce o ejercicio, en condiciones de igualdad, de los derechos humanos y libertades fundamentales en las esferas política, económica, social, cultural o en cualquier otra esfera de la vida pública» ${ }^{15}$. De acuerdo con ello, aquí se utiliza discriminación étnica o racial

8. Por ejemplo, la discriminación contra el pueblo bárbaro por parte de los griegos nada tenía que ver con el concepto moderno de raza. Es en el medioevo cuando el color negro de la piel adquiere un sentido negativo; sin embargo, si se analizan los argumentos modernos sobre la inferioridad de una raza no blanca, se verá que desde la Ilustración se consideró a la población lapona, que, por cierto, es blanca, como inferior, y pese a ello, ha sido objeto de discriminación étnica o racial al igual que la población árabe y la nativa americana. Así, las delimitaciones biológicas se difuminan en lo étnico y viceversa.

9. Ibíd., p. 18.

10. Ibíd., pp. 19-20.

11. RodrígueZ-Piñero, Miguel y Fernández LóPez, María Fernanda: Op.cit., p. 184.

12. Ibíd., p. 185.

13. Ibíd., p. 186.

14. Adoptada y abierta a la firma y ratificación por la Asamblea General de Naciones Unidas en su Resolución 2106 A (XX), de 21 de diciembre de 1965.

15. Artículo 1 de la Convención Internacional sobre la Eliminación de todas formas de Discriminación Racial. En el mismo sentido la define la Declaración de las Naciones Unidas 
con el mismo significado, dado que ambas hacen referencia a construcciones sociales artificiales y difusas basadas en prejuicios sobre características biológicas, de origen o nacimiento, sobre las cuales las personas no tienen capacidad de decisión ${ }^{16}$.

\section{Discriminación racial y por sexo en la Antigüedad}

\subsection{Grecia y la exclusión de lo otro y las mujeres}

En la Antigua Grecia la igualdad tenía que ver con el aspecto económico pues su organización se basaba en una sociedad comunal de los medios de producción, es decir, de la tierra. Los miembros de la comuna poseían la tierra, no como propiedad comunal sino más bien como propiedad privada. Pero una propiedad privada específica: eran propietarios privados pero sólo en cuanto eran miembros de la comunidad; y a su vez eran miembros de la comuna, en cuanto poseedores de la tierra. La propiedad privada estaba, pues, mediatizada por la existencia de la comuna ${ }^{17}$. La forma de organizarse políticamente se realizaba en función de la capacidad económica y desde esa perspectiva sus componentes eran «iguales». Esta línea tenue que trazaba la concepción de igualdad implicaba, en realidad, un privilegio para determinados grupos y no se trató de una idea relacionada necesariamente con la igualdad social ${ }^{18}$, sino de una igualdad política donde un grupo de varones griegos nacidos en la polis, y con propiedades en tanto que ciudadanos, participaban en las decisiones públicas. La existencia de este pequeño grupo de ciudadanos a quienes se les reconocía capacidad jurídica y de obrar plenas, significó la exclusión de «una parte muy importante de la población: los esclavos, las mujeres y los extranjeros» ${ }^{19}$. La participación activa en la polis sólo fue posible con la

sobre la Eliminación de todas las formas de Discriminación Racial de 20 de noviembre de 1963.

16. Lo mismo sucede con la discriminación de las mujeres o por sexo. Ésta tiene que ver con «toda distinción, exclusión o restricción basada en el sexo que tenga por objeto o resultado menoscabar o anular el reconocimiento, goce o ejercicio por la mujer, independientemente de su estado civil, sobre la base de la igualdad del hombre y la mujer, de los derechos humanos y las libertades fundamentales en las esferas política, económica, social, cultural y civil o en cualquier otra esfera». Artículo 1 de la Convención Sobre la Eliminación de Todas las Formas de Discriminación Contra la Mujer. Adoptada y abierta a la firma y ratificación, o adhesión, por la Asamblea General de la ONU en su resolución 34/180, de 18 de diciembre de 1979.

17. De Cabo Martín, Carlos: Teoría Histórica del Estado y del Derecho Constitucional, Vol. I, Barcelona, PPU, 1998, p. 95.

18. TOUCHARD, Jean: Historia de las ideas políticas, Madrid, Tecnos, 1993, p. 31.

19. MARTín VIDA, María Ángeles: Evolución histórica del principio de igualdad y paradojas de exclusión, Granada, Editorial Universidad de Granada, 2004, p. 35. 
existencia de esclavos y de mujeres que liberaron a los ciudadanos de todo trabajo, por lo que podían disponer de tiempo para dedicarse a las actividades políticas.

Al margen de estas prácticas políticas excluyentes, los filósofos griegos presentaron algunas ideas limitadas sobre igualdad. Platón y Aristóteles propusieron ideas de igualdad de y para unos pocos. Tanto en la realidad como en los planteamientos teóricos, la igualdad no tuvo nunca un sentido amplio pues estaba sustentada en la discriminación de las personas en función de su naturaleza. Platón por ejemplo, no «admitió la igualdad fundamental de sus ciudadanos, sino que piensa que cada uno debe ocupar el lugar correspondiente a su naturaleza. De ahí la división de tres clases: filósofos-gobernantes; guardianes-guerreros y obreros-productores $»^{20}$. A cada clase le atribuyó una virtud y así intentó explicar la original desigualdad entre los hombres ${ }^{21}$. Hay que subrayar que no obstante tales ideas, Platón enfatizó la necesidad de educar a las mujeres igual que a los hombres libres ${ }^{22}$. García Gual sostiene que la mezcla de trazos revolucionarios como el comunismo y la igualdad de sexos, a la par que otros un tanto reaccionarios, agudiza el talante utópico de su propuesta $^{23}$.

20. García GuAl, Carlos: «La Grecia antigua», en VAllespín, Fernando (ed.): Historia de la Teoría Política, 1, Madrid, Alianza Editorial, 2002, p. 126.

21. Ibídem. En cierto modo, esta asignación de roles a las personas en función de su «naturaleza» es la que pervive en el derecho de igualdad actual. Así sucede con la discriminación por raza y sexo desde la perspectiva esencialista. Históricamente, a los «naturales» de América y África se les asignó un papel en la sociedad: el ser inferiores, incapaces, menores de edad y por tanto sujetos pasivos en las relaciones de dominación. A las mujeres, por su «naturaleza», se las excluyó de espacio público.

22. Ibídem. Las mujeres en Grecia no tenían acceso a la educación. Al respecto ver: SISSA, Giulia: «Filosofías del género: Platón, Aristóteles y la diferencia sexual», en DuBY, Georges y PerRot, Michelle. Historia de las mujeres. Antigüedad. Vol. 1, Madrid, Taurus, 2000, pp. 89-90.

23. Ibídem. García Gual llama la atención sobre aquellas propuestas «reaccionarias» en donde se plantea la igualdad de sexos. En el mundo académico esta propuesta no se ha visibilizado. El plan de educar a las mujeres ha permanecido oculto y no ha tenido relevancia jurídica ni ha sido considerado un aporte importante para el derecho. Recuérdese que el libre acceso a la educación ha sido una reivindicación feminista hasta entrado el siglo XX en Europa. La historia ha ocultado este proyecto «platónico» tal vez porque se reivindica un derecho para ese otro ser humano que no tiene nada que ver con el sujeto de derecho masculino, blanco, capaz y propietario. Lo mismo sucede cuando se habla de la otredad desde el punto de vista racial o étnico como el caso de la población indígena peruana a quienes se les negó durante mucho tiempo el derecho a la educación. 
Para los griegos la igualdad se reservaba sólo para los helenos libres ${ }^{24}$. Y sobre las teorizaciones de un humanitarismo igualitario que iba más allá de la polis patriarcal, cabe resaltar que en el pensamiento de Antifonte se encuentra «en forma expresa una afirmación de la irrealidad de las diferencias entre nobles y no nobles, entre griegos y bárbaros; resulta muy probable que también criticara la distinción entre libres y esclavos, como nos consta positivamente de Alcidamante y también de Eurípides en distintos lugares $»^{25}$.

Salvo propuestas filosóficas sobre igualdad como la de Antifonte, en realidad los esclavos y las mujeres representaron la gran mayoría de la población griega que vivió en condiciones de clara subordinación constituyéndose esta sociedad en una falsa democracia. En este sentido, se debe hacer dos correcciones a la historiografía hegemónica que sostiene al constitucionalismo occidental. En primer lugar, en esta democracia las mujeres estaban excluidas de toda participación siendo así la democracia griega una democracia eminentemente patriarcal ${ }^{26}$. «El papel de la[s] mujer[es] en cierta manera recuerda al esclavo: de ella depende la reproducción -en este caso biológica- de los ciudadanos (siempre que ellas mismas sean hijas de ciudadano) y son absolutamente pasivas en el orden político. Esta relación mujer esclavo se encuentra explicitada en Aristóteles que compara la condescendencia con los esclavos a la condescendencia con las mujeres (la ginecocracia en los hogares) al señalar que ambas corrupciones conducen a la tiranía ${ }^{27}$. En segundo lugar, aquella participación igualitaria quedaba reducida en la práctica por la enorme influencia de las personalidades más destacadas que pertenecían a las grandes familias $^{28}$, así, la participación y la pugna ideológica por el gobierno de la ciudad «tenía lugar entre los componentes de un reducido círculo ciudadano, cerrado al resto de la población, pues la polis era una comunidad en la que abundaban los exclusivismos $»^{29}$.

24. MARTín VIDA, María Ángeles: Op.cit., p. 34.

25. RODRíGUEZ AdRAdOS, Francisco: La democracia ateniense, Madrid, Alianza Editorial, 1980 , p. 311.

26. El patriarcado como sistema de dominación ha tenido como consecuencia la subordinación histórica de las mujeres, ejerciendo y manteniendo un sistema de dominación, capaz de reproducirse ideológicamente impidiendo la igualdad. Ver: BALAGUER, María Luisa.: Mujer y Constitución. La construcción jurídica del género, Madrid, Cátedra, 2005, p. 24.

27. De Cabo Martín, Carlos: Op.cit., pp. 109-110. Es importante la aclaración que hace De Cabo sobre el sistema patriarcal en la historia del derecho constitucional, son pocos los estudios relativos a esta disciplina que destacan al patriarcado y su fuerte influencia en las teorizaciones jurídico políticas.

28. Ibídem.

29. FINLEY, Moses I.: Los griegos de la antigüedad, Barcelona, Labor, 1985, p. 58.

Feminismo/s 12, diciembre 2008, pp. 271-298 
En este modelo democrático exclusivista, al igual que la condición de las mujeres en situación de discriminación, se encontraban además los «no griegos» o metecos. Así pues, por un lado la igualdad circunscrita a los ciudadanos hombres griegos y ricos encuentra su justificación histórica en el desarrollo económico patriarcal; por el otro, (dado que las razones económicas no son suficientes para explicar la endogamia de la polis) al factor económico hay que añadirle discriminaciones por razón de nacimiento y de raza ya que, por ejemplo, lo extranjero fue excluido de la ciudadanía y sólo podían ocuparse de aquellos trabajos en que los ciudadanos podían embrutecerse. En este sentido, existió un rechazo hacia los bárbaros y hacia los pueblos de lengua diferente a la griega. Sin embargo, existieron críticas a estos prejuicios étnicos como cuando el sofista Antifonte consideraba «como arbitraria e innatural la distinción entre griegos y bárbaros $»^{30}$. Sobre esta base, cabe afirmar que en esta sociedad esclavista y patriarcal, existió la idea de discriminación étnica y racial ${ }^{31}$ y su máxima expresión se encuentra en la situación de los esclavos y metecos y en la exclusión de las mujeres. Esta discriminación y desigualdad evidentes fueron concebidas como un hecho normal y natural y el grupo dominado lo aceptaba «por la coacción que sobre ellos opera imponiéndoseles la idea de que es algo "natural», que la desigualdad entre los hombres es un hecho natural e inevitable que forma parte del orden social $»^{32}$. La función ideológica permitió que las relaciones desigualitarias se interpretaran como algo normal, natural ${ }^{33}$.

\subsection{Roma y las discriminaciones ancestrales: sexo y raza}

Roma fue una sociedad desigualitaria y violenta por antonomasia ${ }^{34}$. En esta sociedad aparece el individuo, que es lo que lo diferencia de Grecia donde

30. García GuAL, Carlos: Op.cit., pp. 72 y 146-166.

31. Ibidem. Ver además, SANTIAGO, Rosa Araceli: «Griegos y bárbaros: arqueología de una alteridad» Proyecto Trabajo realizado en el marco del Proyecto de Investigación financiado por la DGICYT PS 94-0118, Barcelona, Universidad Autónoma de Barcelona, 19 de diciembre de 1997, <http://ddd.uab.es/pub/faventia/02107570v20n2p33.pdf>, consultado el 24-08-2008. La autora explica sobre la discriminación que practicó el mundo heleno a todo lo «no griego». Todo lo referido al otro, al extranjero era considerado bárbaro. Este término alcanzó considerable contenido peyorativo.

32. De Cabo Martín, Carlos: Op.cit., p. 87.

33. «Desde Aristóteles, la igualdad jurídica se plantea en términos de desigualdades consideradas naturales porque derivan de la naturaleza de las cosas». Ver al respecto: ARNAUD-DUC, Nicole: «Las contradicciones del derecho», en DUBY, George y PERROT, Michelle: Historia de las mujeres..., Vol. 4, op.cit., p. 109.

34. «Roma es un hecho violento, se configura a la ofensiva y no a la defensiva. Histórica y culturalmente, con Roma empieza a existir Occidente». Apuntes del Seminario 
primaba la comuna. Su aparición surge con la propiedad privada y en consecuencia, su Derecho privado -fundado en el patrimonio- dominó la vida social e incluso invadió la vida pública. Tanto Grecia como Roma fueron sociedades esclavistas y patriarcales ${ }^{35}$, donde la idea de igualdad se practicó sólo para grupos de personas muy reducidos en los cuales, la propiedad, el sexo y el factor étnico o racial tuvieron mucho que ver. La historiografía no explica claramente la existencia de la discriminación étnica, sólo la describe como exclusión basada en aspectos sanguíneos, origen territorial y social. Estas barreras sociales odiosas aparecían cuando los grupos entraban en la lucha por el poder siendo una de ellas el linaje (que comprendía el origen de sangre, nacional y social). Así, la discriminación racial o étnica fue evolucionando como instrumento para mantener relaciones de dominación de un grupo sobre otro.

Por la forma como se estructuraron las sociedades antiguas, se verifica que existió una construcción social relacionada con la superioridad e inferioridad de un determinado grupo racial o étnico. Ésta se manifestó en Roma con la hegemonía que durante mucho tiempo ejerció el pueblo etrusco en tanto etnia sobre el resto de los grupos. En este contexto, los grupos discriminados en Roma no tenían que ver con el color oscuro de la piel por lo que, al entrar en contacto con las diversas sociedades, marcaron la otredad con apelativos como «extranjero» o «bárbaro» sin distinguir claramente la diferencia entre rasgos biológicos y rasgos culturales ${ }^{36}$; así lo étnico y racial se fusionaban. Los prejuicios que sustentaban la discriminación racial se caracterizaron por consistir «una censura sur-norte que en el imperio era ya conocida por los contemporáneos: Vitruvio, por ejemplo, escribiendo a comienzos del Principado, estaba convencido -en vista de las condiciones económicas más simples y menos desarrolladas en el norte- de que los hombres del sur eran más

impartido por DE CABO MARTín, Carlos: El concepto histórico de Constitución: La Constitución del Estado Social y su crisis en el contexto de la globalización. Seminario Magistral. Instituto Iberoamericano de Estudios Constitucionales, Universidad de Alicante, 25 de octubre de 2007.

35. Se recalca que la definición que se utiliza aquí no se refiere al gobierno de ancianos bondadosos cuya autoridad proviene de su sabiduría, sino a una situación de dominación y, de explotación (énfasis agregado). PULEO, Alicia: «Patriarcado», en AMORós, Celia (directora): 10 palabras clave sobre mujer, Navarra, Verbo Divino, 1995, p. 21. De acuerdo con A. Jónasdóttir, el patririacado tiene que ver con las relaciones de poder entre los sexos, el sinónimo de este término es «dominación masculina» y su finalidad es la designación de un sistema de poder social y político. (JÓNASDÓTTIR, Anna: El poder del amor. ¿Le importa el sexo a la democracia?, Madrid, Cátedra, 1993, p. 32).

36. Wood, Peter H.: «'If Toads Could Speak: How the Myth of Race Took Hold and Flourished in the Minds of Europe's Renaissance Colonizers», en BOWSER, Benjamin P. (Ed): Racism and Anti-Racism in World Perspective, London, Sage Series on Race and Ethnic Relations, Vol 13, 1995, p. 164.

Feminismo/s 12, diciembre 2008, pp. 271-298 
inteligentes y los del norte más aptos para la guerra ${ }^{37}$. A diferencia de lo que hoy ocurre, la sociedad antigua infravaloraba a la gente del norte. Los prejuicios raciales delimitaron la estructura interna de la sociedad romana así como sus relaciones con otros grupos de extranjeros.

En las sociedades antiguas, los prejuicios raciales sostenían a las relaciones desiguales y servían para legitimar el poder y, además, se materializaron mediante la discriminación evidente, mediante una clara exclusión de grandes grupos sociales la mayoría por su etnia y su sexo. Dentro de la sociedad romana, los patricios justificaron la discriminación racial mediante la construcción de su identidad considerándose como los «buenos» de la sociedad $»^{38}$. No hay que olvidar que este grupo era étnicamente heterogéneo (precisamente por los matrimonios mixtos que posteriormente se prohibieron) al igual que la plebe y toda la sociedad. Tras la pérdida de hegemonía del grupo etrusco, el sustento ideológico de la superioridad de un grupo sobre otro basado en la consanguinidad y linaje no perdió fuerza y continuó legitimando a las nuevas familias nobles. Así, la discriminación étnica llamada discriminación social en la historiografía; fue una constante cuyos efectos se extendieron a lo extranjero. Esto tuvo que ver con la consideración que los ciudadanos romanos tenían de las personas denominadas como «bárbaros», frente a ellos mismos como lo civilizado. Al respecto, en sus escritos, Juvenal soñaba con «una Roma estrictamente latina que conserve las virtudes de las pequeñas ciudades italianas: No puedo soportar, Quirites, una Roma griega ${ }^{39}$, estos prejuicios contra lo extranjero incluyeron al pueblo Galo. Para Roma, era un pueblo bárbaro, inhumano y peligroso ${ }^{40}$, y en el mismo sentido: Cicerón llamaba bárbaros a los Galos de la provincia narbonense ${ }^{41}$. La discriminación de los romanos contra el pueblo Galo perduró durante mucho tiempo y a pesar de «la convivencia de estos pueblos, el estereotipo se mantenía. Las dificultades de identificación de un individuo como galo o romano se plantean en más ocasiones a lo largo de la obra de Tácito. ¿En que medida el origen provincial debe primar sobre otros elementos identificadores de un individuo? ¿Qué ocurre, por ejemplo,

37. Alföldy, Géza: Historia Social de Roma, Madrid, Alianza Editorial, 1987, p. 145.

38. Ibíd., p. 24.

39. TOUCHARD, Jean: Op.cit., p. 81. Nótese cómo en estas ideas aparecía el bosquejo de la actual idea de raza.

40. GONZÁLEZ-CONDE, Pilar: «Romanitas versus Feritas: la condición de los galos en la historia de Tácito», en Biblioteca Virtual Miguel de Cervantes, Alicante, Universidad de Alicante, <http://www.cervantesvirtual.com/servlet/SirveObras/ hist/01383831900359627645802/index.htm>, consultado el 27-08-2008.

41. AlFÖldy, Géza: Op. cit., p. 127. 
con los herederos de dinastías locales educados en Roma? $»^{42}$. Aquí aparece la cuestión del límite de lo racial o étnico, una vez más se constata cómo estas características obedecen a patrones socioculturales artificiales sustentados en meros prejuicios.

Una de las manifestaciones de discriminación racial más clara se puso de manifiesto en la situación de los homines novi. Éstos eran seleccionados en función de sus grandes cualidades y capacidades para ser miembro del estamento principal; pero, en el interior del ordo senatorius nunca se aceptó la entrada de senadores sin origen noble. Éste, siempre que podía se negaba a ceder al homo novus las magistraturas más importantes y, con ellas, el acceso al verdadero poder. La referencia más evidente está en el trato dado a Cayo Mario, a quien, a pesar de sus logros, en las intervenciones públicas, la nobleza siempre le hizo recordar sus orígenes «manchados»» ${ }^{43}$, es decir, por no tener sangre noble, fue ocasionalmente criticado, por ejemplo, cuando Claudio defendió la entrada de los Galos en el Senado. En su discurso fundamentó la incorporación de senadores Galos alegando la pluralidad, por sus orígenes, de los senadores allí presentes ${ }^{44}$. El discurso de defensa de los Galos que hizo Claudio es prácticamente una de las poquísimas referencias jurídico-políticas que hay sobre la idea de no discriminación étnica en Roma.

Tal como sucedió en Grecia, la ciudadanía significó la materialización político-jurídica de la discriminación étnica y por sexo. Uno de los ejemplos es la situación de desprecio hacia los socii que «no tenían derechos políticos de tal forma que no podían contar con la posibilidad de defensa que un simple proletario tenía siempre en la asamblea popular $»^{45}$. La idea de ciudadanía tanto griega como romana, constituye la base premoderna de la exclusión y discriminación ${ }^{46}$, y en concreto, la discriminación racial sigue llenando el contenido jurídico de ciudadanía. Junto con la ciudadanía apareció el hecho religioso para fundamentar aquellas dos formas de discriminación: el cristianismo ${ }^{47}$. La igualdad que incluyó a todas las personas ya se había formulado

42. GONZÁLEZ-CONDE, Pilar: Op.cit. Subrayado agregado.

43. Esta idea de «mancha» estará presente también en el contenido de la discriminación étnica medieval.

44. Ver: TÁcito, Cornelio: Anales, Libro XI, Madrid, Gredos, 1986, pp. 30-35.

45. AlFÖLDY, Géza: Op.cit., p. 81.

46. FerRajoli, Luigi: Derechos y garantías. La ley del más débil, Madrid, Trotta, 1999, p. 117. Además de recalcar que la ciudadanía es el último residuo premoderno de la desigualdad personal, el autor critica el concepto de ciudadanía considerándolo como el gran apartheid que excluye del disfrute de derechos a la gran mayoría de la humanidad. Ibíd, pp. 117 y ss.

47. Gran parte de la literatura jurídica sostiene que el cristianismo subrayó la igualdad esencial de todos los seres humanos ante Dios y, que la imago Dei y la condición

Feminismo/s 12, diciembre 2008, pp. 271-298 
antes con Antifonte e incluso con Séneca, por tanto, a pesar de que el cristianismo haya pregonado la imago Dei, discriminó a las personas por su etnia y por el solo hecho de su sexo. La teoría feminista sostiene que esa alusión al cristianismo como fuente de la idea de igualdad universal en el Derecho romano y en el Derecho Occidental pone en evidencia los sesgos no legítimos que distorsionan la historia y el conocimiento ${ }^{48}$. En realidad esta doctrina justificó el orden injusto establecido, sustentándose en una fuerza sagrada y autogeneradora que impone y sostiene un orden desde arriba estableciendo así límites sociales desigualitarios ${ }^{49}$.

\section{Discriminación racial y por sexo en el Medioevo}

Esta sociedad estaba marcada por una desigualdad evidente y por relaciones de dependencia personales. El carácter desigualitario de esta sociedad radicaba en la subordinación de un individuo a otro ${ }^{50}$, éste fue el panorama medieval con su modo de producción feudal y con su sistema patriarcal. La larga duración del feudalismo que atravesó fronteras continentales y se instauró en América tuvo también su base en la discriminación racial.

personal dotaron de un valor absoluto a todo ser humano por el mero hecho de serlo y que, esta concepción personalista del hombre de inspiración cristiana fue decisiva para una adecuada fundamentación de los derechos humanos y su universalidad. FERNÁNDEZ, Encarnación: Igualdad y derechos humanos, Madrid, Tecnos, 2003, p. 27. Estas afirmaciones no son ciertas ya que el cristianismo nunca consideró igual a las mujeres y en el caso de la justificación de la colonización de América, el cristianismo no defendió la igualdad de las poblaciones nativas americanas y, sí su dominación puesto que consideró a esta gente como infieles e incapaces.

48. BEAuvoir, Simone: El segundo sexo. Los hechos y los mitos, Tomo I, Buenos Aires, Siglo Veinte, 1987, pp. 188-192, y Amorós, Celia: Tiempo de feminismo. Sobre feminismo, proyecto ilustrado y postmodernidad, Madrid, Cátedra, 2000, pp. 377-395. San Pablo manifestó que: «Las mujeres escuchen en silencio las instrucciones con entera sumisión. Pues no permito a las mujeres que enseñe ni tome autoridad sobre el marido; mas estése callada. Ya que Adán fue formado el primero, y después Eva». En el Génesis, 3 se sentencia: «Das a luz con dolores y angustias, mujer; sufres la atracción de tu marido y él es tu señor. ¿E ignoras que eres Eva? Vive aun en este mundo la sentencia de Dios contra tu sexo. Vive, pues, y es necesario que sea así, como acusada. Eres la puerta del diablo. Eres tú quien ha roto el sello del Árbol; eres la primera que ha violado la ley divina; eres tú quien ha embaucado a aquel a quien el diablo no pudo atacar; eres tú quien ha vencido tan fácilmente al hombre, imagen de Dios. Es tu salario, la muerte, lo que ha valido la muerte al hijo de Dios. ¿Y aún piensas cubrir de adornos tus túnicas de piel?» Ver: AleXANDRE, Monique: «Imágenes de mujeres en los inicios de la cristiandad», en DubY, Georges y PerRot, Michelle: Historia de las mujeres.., Vol. 1, op. cit., pp. 488-489.

49. FitZPATRICK, Peter: La mitología del derecho moderno, Madrid, Siglo XXI, 1998, p. 17.

50. BLOCH, Marc: La sociedad feudal. Madrid, Akal, 1986, p. 161. 
En la Europa medieval, su pluralidad estaba determinada por el origen de sus habitantes de tal modo que se les clasificaban como manumitidos, herederos de manumitidos, bastardos, extranjeros o forasteros y, dentro de los cuales estaban los colectivos de gitanos, sarracenos o moriscos y judíos, todos formaban parte de la masa de siervos y junto con ellos, en la misma situación, estaban las mujeres. La nobleza estaba conformada por antiguos linajes de jefes locales, históricamente, ésta no dejó de «conservar más de un rasgo de su primitivo prestigio de razas sagradas $»^{51}$. El vínculo sanguíneo para clasificar a las personas se reforzó y siguió configurando la estratificación social desigual. Esta desigualdad se plasmó en el ámbito político y jurídico a través de los estatutos de «limpieza» de sangre; de las leyes de expulsión de etnias no blancas y no cristianas; de leyes que ponían en duda la naturaleza humana de gente no europea ni blanca (como la que afectó a la población nativa americana) y en el contenido del Derecho de conquista y de guerra.

\subsection{La desigualdad medieval: raza, sexo y religión}

En el territorio medieval fragmentado y lleno de localismos, las ideas propias de la concepción imperial y religiosa se retroalimentaron. La concepción religiosa como soporte del ideal universalista y unitario recorrió el feudalismo reinventando nuevas prácticas de discriminación. La Iglesia junto con el poder temporal utilizó la discriminación étnica para conservar el poder, siendo la doctrina herética uno de sus principios para sustentar la desigualdad de las personas y precisamente según éste es en Galia, antaño discriminada por el pueblo romano, donde apareció una de las primeras manifestaciones de herejía ${ }^{52}$, así, sobre la base de prejuicios étnicos se consideró herejes y maniqueos a los colectivos moro, judío, gitano, indio salvaje, negro y a todas las mujeres. En su fundamento sobre la herejía aludió a que estas personas «adoraban un diablo que se les aparecía en forma de un negro ${ }^{53}$. Así, lo oscuro, lo negro empezó a relacionarse con lo malo y por tanto, con lo no cristiano. Esta connotación de lo negro con lo negativo es una herencia de la simbología de los colores de la civilización grecorromana y fueron los prejuicios medievales los que le dieron «una connotación monstruosa a rasgos físicos como el color de

51. Ibíd., p. 304.

52. DuBY, Georges: El año mil. Una nueva y diferente visión de un momento crucial de la historia, Barcelona, Gedisa, 1988, p. 87.

53. Ibíd, p. 88. Así empezó a asociarse la piel negra con lo negativo dándosele un sentido peyorativo.

Feminismo/s 12, diciembre 2008, pp. 271-298 
la piel $\aleph^{54}$. El color sintetizaba una jerarquía y una evaluación religiosa que dio contenido a la cultura secular occidental. Al igual que sucedió con el sexo, se rescató la simbología de los opuestos que los filósofos antiguos habían construido y sobre esa base le dieron un significado simbólico a lo negro ${ }^{55}$. A esta «construcción del Otro se le añade la imagen de salvaje, es decir, indómito, y con una sexualidad incontenible. El salvaje representaba el polo opuesto de la vida cristiana ${ }^{56}$. Más tarde, durante la conquista del territorio americano esta concepción sobre la otredad cuestionó la naturaleza humana de su población nativa.

En la sociedad feudal y patriarcal las manifestaciones que atentaban contra la religión se relacionaron con las mujeres. Por ejemplo, el cristianismo sostuvo que la herejía de Orleáns nació por causa de las mujeres presas del diablo que con el veneno de su infamia corrompían a muchos hombres, «no sólo a los necios y a las gentes simples, sino incluso a la mayoría de quienes en la propia orden de los clérigos pasaban por ser los más eruditos» ${ }^{57}$. El desarrollo del Derecho canónico se sustentó en la discriminación por sexo y raza durante toda la etapa feudal y cuando se trataba de las mujeres, las leyes de la Iglesia las discriminaban ostentando una justificación divina. Tomando en cuenta que durante mucho tiempo la esclavitud coexistió con el feudalismo, el ámbito doméstico era el espacio donde se encontraban recluidos esclavos de ambos sexos y mujeres europeas. Así, sexo y raza caminaron de la mano para mantener las relaciones de dominación y explotación. En el caso de la discriminación contra lo judío la historiografía pone en evidencia su vínculo

54. Gimeno JimÉnez, Leonor: Psicosociología del racismo en España, Madrid, Universidad Complutense de Madrid, 2004, p. 25, <http://www.ucm.es/BUCM/tesis/cps/ucmt27858.pdf>, consultado el 28-08-2008.

55. Una vez más sexo y raza parecen desarrollarse juntos en el ámbito de la discriminación. Sobre la simbología de los opuestos en la Grecia antigua, De Cabo resalta que «el recurso a los opuestos tiene, entre otras, una notable manifestación en el distinto valor que se atribuye a la contraposición derecha-izquierda: en Homero la derecha es lo positivo, la fuerza y la vida, mientras que la izquierda es lo negativo, la debilidad y la muerte; en los pitagóricos, la derecha es lo bueno, la izquierda lo malo (...); en la escuela hipocrática se vincula la idea de derecha al varón y la de izquierda a la mujer». De Cabo resalta que estas representaciones en torno a la significación derecha-izquierda influyeron en las tácticas guerreras y en el ámbito de las instituciones sociales. DE CABO, Carlos: Op.cit., p. 134.

56. BASTIDE, R.: «Colour, Race, and Christianity», en J.H. Franklin (Ed.) Colour and Race, Boston, Houghton Mifflin, 1968, p. 36, citado por GIMENO JIMÉNEZ, Leonor: Op.cit., p. 25.

57. DuBY, Geroges: El año mil..., op. cit., p. 88. Nótese el contenido discriminador hacia dicho pueblo y las mujeres. Fueron comunes los casos de brujería cuyo castigo por la Inquisición se dirigió muy especialmente a las mujeres. 
con el sometimiento de las mujeres. El Concilio de 1215, impuso el uso de una vestimenta distintiva, para impedir que los cristianos se unan a las mujeres judías sin saberlo ${ }^{58}$. Este edificio social y jurídico medieval que estaba caracterizado por una diversidad de poderes todos jerarquizados, no obstante su pluralismo y divergencia siempre coincidieron en los criterios de discriminación por sexo y raza para conservar su poder por lo que, la discriminación por sexo afectó no sólo a las mujeres de otras etnias sino a las propias mujeres occidentales cristianas. Frente a esta discriminación hay que destacar la critica que realizó el movimiento intelectual La Querella des Femmes cuyos orígenes se remontan al siglo XIV o tal vez mucho antes. El contenido del pensamiento crítico La Querella de las Mujeres se consolidó con el trabajo intelectual de Christine de Pizan en el siglo XV, del que cabe destacar su obra La Ciudad de las Damas. Mediante este movimiento se rebatieron muchos de los contenidos del pensamiento misógino bajomedieval y demostraron que las mujeres eran tan valiosas como los hombres ${ }^{59}$. No obstante estas reivindicaciones la discriminación de las mujeres medievales se fue fortaleciendo.

Respecto a la discriminación racial medieval, una de sus máximas expresiones se encuentra en la Guerra Santa ${ }^{60}$. La defensa de la religión cristiana se sustentó en la violencia construyéndose con ella la idea de «limpieza» de sangre $^{61}$. Sobre esa base se justificó la muerte y expulsión del territorio español de los colectivos judío, moro y gitano. A las mismas mujeres europeas les afectó negativamente en todo sentido, en la medida en que se las concibió como pecadoras por naturaleza, lo cual repercutía en el Derecho canónico.

En España, con los Reyes Católicos se inició una política de homogeneidad cultural y religiosa que produjo graves consecuencias para los grupos étnicos minoritarios ${ }^{62}$, el objetivo fue la conservación de una casta conside-

58. FONAY WEMPLE, Suzanne: «Las mujeres entre finales del siglo V y finales del siglo X» en Duby, Georges y Perrot, Michelle: Historia de las mujeres. La Edad Media. Vol. 2, op. cit., p. 300.

59. RIVERA, María Milagros. «El cuerpo femenino y la «querella de las mujeres» (Corona de Aragón, siglo XV)» en Duby, Georges y Perrot, Michelle: Historia de las mujeres. La Edad Media. Vol. 2, op. cit., pp. 609-610.

60. En 1095 el Papa francés Urbano II convocó a todos los pueblos católicos de occidente a una Guerra Santa, que, mediante las Cruzadas, duró desde el siglo XI al XIII.

61. Respecto a la expresión «limpieza étnica», para Van Dijk, «limpieza» es un eufemismo en la doctrina sobre discriminación racial por lo que considera que es más correcto llamarle exterminio étnico [VAN Dijk, Teun A. (coord.): Racismo y discurso en América Latina, Barcelona, Gedisa, 2007, p. 22]. De acuerdo con la posición del autor, en este texto «limpieza de sangre» se utilizará entrecomillada.

62. Informe de la Subcomisión, creada en el Seno de la Comisión Política Social y Empleo, para el estudio de la problemática del pueblo gitano. Boletín Oficial del Congreso de los Diputados, VI Legislatura, Núm., 520, Serie D General, 17 de diciembre de 1999. 
rada la mejor respecto de otras que no reunían características relacionadas con la ascendencia y la religión. Según las definiciones de la época, «casta» significó «buen linaje» «ya que a la descendencia biológica estaba vinculada a un juicio de valor, así, el adjetivo «castizo» fue definido como «de buen linaje y casta» $»^{63}$. «Casta»y «castizo» definieron la «castidad» refiriéndose a la ausencia de mezcla y de contaminación y de ahí a un estado de pureza religiosa ${ }^{64}$. Esta política llegó a determinar las fronteras raciales sobre la base del hecho religioso, y su instrumento fue la Inquisición. Este tribunal determinaba el estatus jurídico de las personas donde la categoría de «maculados» o cristianos impuros implicaba una «mancha» con sangre judía o musulmana ${ }^{65}$. Aquí encontramos una similitud con la discriminación de los hombres nuevos en la antigua Roma.

Las relaciones de explotación y dominación basadas en la infravaloración de las personas de piel oscura y de una religión diferente mantenían el sistema económico para el disfrute de lo cristiano blanco. Así es como se fue construyendo la «civilización» occidental y posteriormente el hombre «genérico» hasta llegar al sujeto de derecho. La idea de «limpieza» de sangre junto con el feudalismo fueron trasladados hacia América donde la exclusión de lo indio y lo negro sustituyó a lo moro, judío y gitano ${ }^{66}$. Así pues, en el medioevo, además de los prejuicios heredados desde la antigüedad se sumaron otros muchos construidos por la doctrina cristiana. Sobre la base del hombre cristiano blanco y europeo se estableció la estratificación social.

63. STAllaert, Christiane: Etnogénesis y etnicidad en España: una aproximación históricoantropológica al casticismo, Barcelona, Proyecto A, 1998, pp. 21 y 22.

64. Ibídem.

65. Ibíd., pp. 22-27.

66. La constante presencia de Santiago Mataindios en las crónicas de la Conquista del nuevo mundo por parte de los españoles demuestra la gran influencia de la Iglesia y su pensamiento altamente discriminador. El Santiago Matamoros europeo pasó a ser denominado Mataindios en América. Su contextualización respondía a la necesidad inmediata de incluir viejas identidades medievales en nuevos espacios geográficos, sobre la base de la exclusión de la otredad. Sobre la extensión del dominio hegemónico de lo blanco cristiano en el Nuevo mundo y la simbología de Santiago, ver: DomínGUEZ, Javier: «Santiago Mataindios: la continuación de un discurso medieval en la Nueva España», Nueva Revista de Filología Hispánica, vol. 54, núm. 1, El Colegio de México, México, pp. 33 a 36. 


\section{Igualdad y discriminación en el estado absoluto}

Los efectos resultantes del desarrollo progresivo del comercio especialmente a partir del «mercado mundial ${ }^{67}$ que se abrió en el siglo XV con los grandes «descubrimientos» ${ }^{68}$, supusieron significativos cambios en la producción económica y en la forma de ejercer el poder. Ello trajo como consecuencia la aparición del Estado moderno con sus notas características: la centralización política, la unificación territorial y fortalecimiento del poder; y la lenta aparición de un nuevo modo de producción: el capitalismo. En esta etapa de transición del feudalismo al capitalismo las desigualdades se acentuaron, y el instrumento que facilitó su consolidación fue el Estado Absoluto. El nuevo sistema económico encontró apoyo para poder funcionar en el Derecho romano, ya que éste le aportaba mayor seguridad jurídica al tráfico económico ${ }^{69}$. Precisamente este viejo Derecho privado, eminentemente individualista y patriarcal fue el sustento del modo de producción que empezaba a dominar las relaciones sociales de tal modo que la base privatista y desigualitaria de la antigua Roma fue introduciéndose en lo público del mundo moderno capitalista y, en concreto, en la teoría del poder político, por ejemplo, en las teorizaciones que justificaron el poder del Estado absoluto.

El eje para elaborar la idea de poder político fue la familia patriarcal donde las mujeres estaban en condiciones de total subordinación puesto que el Derecho romano les negó una posición igualitaria respecto del hombre. Así, Bodino y Hobbes, autores que aportaron a la construcción del pensamiento sobre Estado Absoluto, concibieron al poder del Estado como el poder que ejercía el padre, en tanto amo y soberano de su familia. En efecto, Hobbes lo comparó con el poder del padre que concentra el poder -porque la mujer le cede el gobierno- y lo ejerce sobre el resto de los componentes de su familia que son de su propiedad (hijos, siervos, mujer ${ }^{70}$. Por su parte Bodino entendió el

67. Expresión de Marx aplicada a esta época. MARX, Carlos: El Capital, Vol. I, México, Fondo de Cultura Económica, p. 637, citado por DE CABO MARTín, Carlos: Op.cit., p. 293. Esta expresión surge desde una visión eurocéntrica como consecuencia del llamado «descubrimiento» de América.

68. Sobre la expresión descubrimiento de América, desde la perspectiva iberoamericana, este hecho más que un «descubrimiento» significa una conquista o invasión y en todo caso, el encuentro y la fusión de dos pueblos, en fin, de dos mundos. SOBERANES FERNÁNDEZ, José Luis (ed.): El primer constitucionalismo iberoamericano, Madrid, Marcial Pons, 1992, p. 11. Por su contenido eurocéntrico, se ha considerado la utilización entrecomillada de «descubrimiento».

69. CARMONA CuENCA, Encarnación: «El Estado en su dimensión histórica», en AyUSO TORRES, Manuel: Manual de derecho constitucional, I, Madrid, Colex, 1997, pp. 38 y ss.

70. Ver la crítica a Hobbes desde la perspectiva de género en JÓNASDÓTTIR, Anna: El poder del amor..., op.cit., pp. 176-192.

Feminismo/s 12, diciembre 2008, pp. 271-298 
poder en el mismo sentido y añadió que el gobierno ejercido por las mujeres va contra la naturaleza por lo que, en su defensa del orden existente basado en poder masculino y apoyándose en la referencia de las Leyes Fundamentales o Leges Imperii, fundamentó la prohibición de las mujeres de ocupar el trono de Francia $^{71}$. Así sobre la base de la exclusión de las mujeres se desarrolla la idea de poder político, lo cual va a repercutir más adelante en la teorización de los derechos fundamentales, puesto que el hombre «genérico» del Renacimiento y el sujeto de derecho consolidado tras la Ilustración seguirá sosteniéndose en la figura del pater, es decir, del individuo propietario de sus bienes patrimoniales y de su familia. Obviamente, esta defensa de un poder supremo político monopolizado en una sola persona que consolidó al absolutismo, obedecía a la desigualdad de los hombres europeos pues sus diferencias continuaban fundándose en el nacimiento, en el origen familiar, esto es, en la etnia o raza y, la esclavitud también se mantuvo, especialmente por los prejuicios heredados del medioevo que se basaron en el desprecio de la población de piel oscura.

Así, un nuevo modo de producción empezó a convivir con dos viejas formas de discriminación: por raza y sexo. Los reyes de las monarquías absolutas que se configuraron en Europa -continental- desde mediados del siglo $\mathrm{XV}^{72}$, se fueron convirtiendo progresivamente en auténticos soberanos, que se reservaron los derechos exclusivos de emitir moneda y de exigir impuestos, de crear las leyes y de administrar justicia contando con una administración territorial y con un funcionariado dependiente ${ }^{73}$. En la práctica, la sociedad seguía estructurada de la manera feudal con la diferencia que había una burguesía que unida al pueblo llano o tercer estado, reivindicaba igualdad, mediante algunas manifestaciones violentas ${ }^{74}$. Las formas de discriminación por etnia y sexo pervivieron.

\section{Entrada a la Modernidad y discriminación por raza y sexo: el Renacimiento}

Dos fueron los valores que sustituyeron a los antiguos: el dinero (el resultado obtenido) y el talento (la capacidad técnica) reemplazaron al nacimiento y la posición social ${ }^{75}$. Así las relaciones sociales antaño concebidas por el origen,

71. De Cabo Martín, Carlos: Op.cit., p. 355.

72. Ibíd., p. 295.

73. MARTín Vida, María Ángeles: Op.cit., p. 69.

74. HuizingA, Johan: El otoño de la Edad Media, Madrid, Alianza, pp. 82 al 84. No se habían corregido situaciones de desigualdad como el escaso aprecio a la burguesía y el menosprecio al tercer estado.

75. De CABO, Carlos: Op.cit., p. 309. 
la casta y la etnia sufrieron algunos cambios, lo que repercutió también en el poder de la Iglesia sobre la sociedad. Precisamente esos valores que tenían el carácter de amorales e individualizadores dieron lugar al comienzo de un proceso de secularización, su sustento estaba en las ideas renacentistas.

En lo que respecta a los atisbos sobre igualdad en este contexto, cabe resaltar las aportaciones de Tomás Moro, con su Utopía. Su obra, que fue «el resultado de la influencia del pensamiento renacentista y del descubrimiento de América ${ }^{76}$, representa una de las más duras críticas al sistema político europeo de la época y al egoísmo en que se asentaba. Junto con algunas utopías igualitarias, intelectuales eclesiásticos plantearon los bosquejos de la igualdad formal respecto de las poblaciones nativas americanas: son los llamados «defensores de los indios» entre los que cabe destacar a Las Casas y Vitoria. Según un sector mayoritario del Derecho éstos «sentaron las bases doctrinales para el reconocimiento de la libertad y dignidad de todos los hombres» ${ }^{77}$. En realidad, se formularon la forma de legitimar la guerra y la propiedad de aquellos territorios (las encomiendas fueron el eje de los argumentos lascasianos), pero nunca se defendió la igualdad entre hombres indios y europeos precisamente por los prejuicios raciales de la época. Las Casas defendió la colonización y la naturaleza inferior de los «indios», de ahí que solicitara que la Corona se hiciese cargo de ellos, no obstante se le ha atribuido un valor democrático y humanista a sus argumentos; en todo caso, se trata del precedente del discurso formal encubridor de desigualdades propio del constitucionalismo liberal por su contenido discriminador.

Lo sucedido con la población nativa americana significó la consolidación del eje del Renacimiento: el «hombre "genérico», universal, lo que conlleva la afirmación de una naturaleza humana única tanto en el tiempo como en el espacio (lo que no dejaba de plantear el problema de los pobladores de otros mundos) $\gg^{78}$. En este momento nace la idea del hombre individualizado y libre en el seno de la burguesía, quedando fuera de esta representación las mujeres, las poblaciones diferentes como la gitana y americana y aquellas personas sin propiedad. Al lado de las ideas humanistas, la sociedad europea seguía

76. Rodríguez Santidrián, Pedro: «Introducción», en Moro, Tomás: Utopía. Madrid, Alianza, 1998, p. 9.

77. Pérez Luño, Antonio E.: Los derechos fundamentales, Madrid, Tecnos, 2004, p. 31. En el mismo sentido Beuchot, Mauricio: Derechos humanos. Historia y filosofía, México, Fontamara, 1999, pp. 138-144. Respecto de la supuesta defensa de los «derechos humanos» de los «indígenas» ya lo avanzó en 1992 PÉREZ LuÑo, Antonio-Enrique, en su libro La polémica sobre el Nuevo Mundo. Los clásicos españoles de la filosofía del derecho, Madrid, Trotta, ver especialmente: pp. 145-186.

78. DE CABO, Carlos: Op.cit., p.316.

Feminismo/s 12, diciembre 2008, pp. 271-298 
marcada por las jerarquías medievales. «El nacimiento seguía determinando la pertenencia a una clase social y con ello quedaba condicionada la vida entera del individuo» ${ }^{79}$. Dado que en esta época Europa tuvo mayor contacto con pueblos de pigmentación más oscura procedentes de África, Asia y América, el pensamiento occidental se desarrolló sobre la base de prejuicios de lo «desconocido». Ello ocasionó la exacerbación del individualismo y de la riqueza que llegó a plasmarse en las teorizaciones sobre la ciudadanía. Con Locke se planteó la limitación del poder político sólo a los propietarios y la exclusión de las mujeres y los pobres, en tanto que defensor de la burguesía ensalzó al hombre «genérico»: propietario, blanco, europeo, dotado de razón en cuya abstracción no estaba presente el nativo americano ni las mujeres ${ }^{80}$.

\section{La Ilustración y la legitimación de la aristocracia blanca y masculina}

Los filósofos ilustrados abrazaron también la creencia en el progreso y en que bastaba con modificar las leyes del mundo para mejorar la condición humana. En su empeño, continuaron manteniendo las dos formas de discriminación histórica: por etnia y sexo. Con la entrada del capitalismo, el patriarcado seguía intacto. Junto con la discriminación contra lo gitano, moro, e «indio», las mujeres siguieron marginadas. En este contexto, el discurso de la Ilustración respecto de la igualdad fue sólo una afirmación implícita de la igualdad de todos los hombres, en tanto que dotados todos ellos de razón y aspirantes a la consecución de la felicidad ${ }^{81}$. Este movimiento llevaba un germen: el individualismo humanista burgués sustentado en el hombre europeo que necesitaba superar su mayoría de edad y desarrollar sus actividades económicas tal y como lo definió Kant: la Ilustración es «la salida del hombre

79. MARTín VIDA, María Ángeles: Op.cit., p 72.

80. La importancia de la identificación del hombre producto de la modernidad ha servido a las teorías críticas sobre igualdad para concluir que históricamente esta abstracción unilateral y pretendidamente universal ha ocultado discriminaciones como la racial. La teoría feminista denuncia que las mujeres no han sido incluidas en la abstracción «sujeto de derechos». En el mismo sentido opina Cámara Villar: hasta el presente, la situación de la[s] mujer[es] se ha venido caracterizando justamente por su más que evidente papel de «no sujeto» en el conjunto social (Introducción de CÁmARA VILLAR, Gregorio, en MARTín VIDA, María Ángeles: Fundamento y límites constitucionales de las medidas de acción positiva, Madrid, Civitas, 2002, p. 13). Cabe resaltar, respecto de la discriminación étnica en el Perú, que la población nativa se viene caracterizando por su evidente papel de «no sujeto» de derecho en el conjunto de la sociedad peruana por que es un colectivo afectado por la discriminación racial.

81. MARTín VIDA, María Ángeles: Op.cit., p. 79. 
de su minoría de edad» ${ }^{82}$. Así se va consolidando el pilar del pensamiento ilustrado: individuo, con autonomía y capacidad para ejercer su libertad, los iguales eran éstos: todos los hombres blancos dotados de razón, capacidad, conocimiento, mayores de edad y obviamente, propietarios. Éstos accedieron a la ciudadanía excluyendo al resto mediante el sufragio censitario de modo que paulatinamente, sexo y raza van ir delimitando el ejercicio pleno de los derechos fundamentales ${ }^{83}$.

\subsection{Crítica a la razón discriminadora: la Teoría Feminista}

Fueron las propias mujeres europeas dentro de la Ilustración con la teoría feminista quienes criticaron la discriminación por sexo y además los prejuicios raciales. El feminismo brindó una categoría que sirvió para la crítica a la discriminación por sexo y raza: el hombre producto de la Ilustración que «nació como un referente universal que no era ni mujer, ni indio, ni negro, ni esclavo -Francia revocó en 1802 la abolición de la esclavitud votada en $1797-$, y que se encarnó en la figura del varón blanco y propietario» ${ }^{84}$. Este

82. Ver: KANT, Immanuel. Crítica de la razón pura; ¿Qué es la Ilustración?, Valencia, Universidad de Valencia, 1990. También, siempre que sea posible, se facilitará la URL sobre obras de los autores clásicos del Derecho occidental disponibles en la Red. Kant, Immanuel. ¿Qué es la Ilustración?, <http://www.cibernous.com/autores/kant/textos/ ilustracion.html>, consultado el 1-09-2008. El autor señala como una verdad la culpabilidad de cada individuo de no querer llegar al conocimiento y afirma que todas las mujeres son culpables de su falta de uso de razón. Encontramos aquí un pensamiento discriminador por sexo, pues para este autor, la ilustración desde ya es un imposible para el bello sexo, Ibídem.

83. Con la aparición de los Estados independientes, a las poblaciones indígenas, por influencia de la Ilustración, se les negó la capacidad de razonar y sobre esa base la ciudadanía. En el Perú, durante mucho tiempo, esta población no ha sido considerada como sujeto político por no estar alfabetizada, ni tener propiedades. La élite consideró que no podía votar por no estar capacitada ni dotada de autonomía para decidir el voto. Villarán, Manuel Vicente: Anteproyecto de Constitución de 1931. Exposición de Motivos y Texto. Lima, P. L. Villanueva, 1962, p. 27. Esta argumentación que negaba el derecho de participación política a las poblaciones indígenas es similar a la utilizada para fundamentar la exclusión de las mujeres como ciudadanas plenas. Así, el pensamiento ilustrado patriarcal consideró que éstas no tenían capacidad suficiente para discernir sobre su voto. Ver al respeto el Discurso de Clara Campoamor ante las Cortes el 1 de octubre de 1931, donde quedaría aprobado el voto femenino en España, disponible en el portal de la Red Feminista de Derecho Constitucional, <http://www.feministasconstitucional. org/content/discurso-de-clara-campoamor-1931> consultado el 1-09-2008.

84. «Esta expresión fue popularizada por la literatura feminista de los años setenta y ochenta, que ha realizado importantes contribuciones para el análisis del universal euro-americano». BESSIS, Sophie: Op.cit., p. 39. Una crítica en el mismo sentido y utilizando la contribución de la teoría feminista la hace Ferrajoli. El autor señala que si una «diferencia» como la sexual resulta de hecho ignorada o discriminada, ello no quiere

Feminismo/s 12, diciembre 2008, pp. 271-298 
universal europeo acabó siendo plasmado en el Derecho como el sujeto jurídico, es decir, como centro abstracto de imputación de derechos y obligaciones. Así, la idea de este sujeto surgido de la modernidad fue a la vez su elemento básico. Esta idea es en sí misma no religiosa, laica, en cuanto implica la capacidad del hombre para determinarse, para construir la Historia que, desde ese momento, se puede entender como racionalidad y no como providencialismo. Es lo que se ha llamado el Discurso de la Modernidad y que puede rastrearse desde el Renacimiento, Descartes y su configuración del sujeto «cogitans», la Ilustración, la concepción del yo kantiano y la Revolución francesa como proclamación del sujeto en libertad ${ }^{85}$.

Con el ejercicio de esa misma razón ensalzada por los ilustrados, el pensamiento feminista reivindicó una igualdad universal desvelando los intereses y el carácter discriminador y patriarcal de los defensores de la razón y progreso. El feminismo criticó a la Ilustración no sólo por su discriminación por sexo sino también por raza, por ejemplo, las sufragistas reivindicaron la abolición de la esclavitud de la población negra sin distinción de sexo y desenmascararon su discurso basado en la igualdad formal. Denunciaron los intereses del sistema de dominación patriarcal y también racial, los cuales se erigían como pilares históricos de un triunfante capitalismo.

De las tantas aportaciones del feminismo, cabe destacar a Poulain de la Barre que propuso la necesidad de erradicar los prejuicios que invadían la razón fundamentada ciegamente por los ilustrados ${ }^{86}$. Para este filósofo cartesiano la desigualdad de los sexos es el prejuicio de los prejuicios, el más viejo y universal ${ }^{87}$. Hay que recordar que estos prejuicios no sólo tenían que ver

decir que la igualdad es «contradicha», sino simplemente que es violada. Considera por tanto, que tal violación de la igualdad ha sido ocultada durante mucho tiempo por el hecho de que el modelo normativo de la igualdad había sido pensado con referencia exclusiva al sujeto macho, así como blanco, propietario, instruido y ciudadano (FERRAJOLI, Luigi: Op.cit., p. 80). Énfasis agregado.

85. De Cabo Martín, Carlos: «El sujeto y sus derechos» en Teoría y Realidad Constitucional, $\mathrm{n}^{\circ}$ 7, Primer semestre, Madrid, UNED, 2001, pp. 117-118. Sobre el origen de este sujeto desde el feminismo constitucional ver: ESQUEMBRE, María del Mar: «Género y ciudadanía, mujeres y Constitución», en Montesinos, Nieves y ESQUEMBRE, M. a del Mar (coords.): Mujeres y Derecho. Revista Feminismo/s, 8, CEM, Alicante, Universidad de Alicante, (diciembre de 2006), pp. 35-51.

86. Amorós, Celia: Tiempos de feminismo..., op. cit., pp. 125 y ss. Puede afirmarse que Posada tomando como referencia a Poulain, hace una crítica al prejuicio jurídico y tradición jurídica en relación con la discriminación por sexo (Ver: POSADA, Adolfo: Feminismo, Madrid, Librería de Fernando Fé, 1899, pp. 271 a 275).

87. De Miguel Álvarez, Ana: «El feminismo en clave utilitarista ilustrada: John S. Mill y Harriet Taylor Mill», en Amorós, Celia y De Miguel, Ana (Eds.): Teoría feminista: de la Ilustración a la globalización, Vol. 1, Madrid, Minerva Ediciones, 2005, p. 185. 
con la infravaloración de las mujeres sino también del resto de las poblaciones no europeas. El planteamiento de Poulain cartesianamente nítido, podría resumirse así: el prejuicio relacionado con la desigualdad entre los sexos es el más obstinado y ancestral, ergo si podemos refutarlo a fortiori lo podremos hacer con todos los demás ${ }^{88}$. Poulain, pues, sienta las bases del Derecho antidiscriminatorio.

Las exigencias de erradicación de los prejuicios como construcciones sociales sobre la base de la raza y sexo están presentes también en la obra de Wollstonecraft en donde rebate las ideas de ilustrados como Rousseau de que la subordinación de las mujeres sea natural e inevitable y explica que, por el contrario esa subordinación es histórica y cultural ${ }^{89}$. Criticó también la discriminación racial, así Wollstonecraft manifestó que someter a las mujeres a las restricciones severas que impone el decoro significaba limitarlas en su capacidad de actuar. Y se preguntó: «¿Por qué someterla al decoro -al decoro ciego- si es capaz de actuar por un principio más noble, si es heredera de la inmortalidad? ¿Siempre se ha de producir el azúcar mediante sangre vital? ¿Ha de someterse la mitad de la especie humana, como los pobres esclavos africanos, a los prejuicios que la brutaliza, cuando los principios serían una defensa más segura, sólo para endulzar la copa del hombre? ${{ }^{90}}^{90}$.

Cabe recordar que ya Montesquieu en su Espíritu de las Leyes había justificado la necesidad de la esclavitud de las poblaciones africanas afirmando que «el azúcar sería demasiado caro si no se obligase a los negros a cultivar la caña dado el exterminio de los pueblos de América. Esos esclavos son negros de los pies a la cabeza (...). No se concibe que Dios, un ser tan sapientísimo, haya puesto un alma en un cuerpo tan negro, y un alma buena, es aún más inconcebible en un cuerpo semejante» ${ }^{91}$. Wollstonecraft alude al azúcar cuando se refiere a la opresión de las mujeres e indirectamente recuerda la situación de los esclavos negros de África y al exterminio de los pobladores nativos de América. El azúcar que se ha de producir por las relaciones de dominación

88. Amorós, Celia y Coвo, Rosa: «Feminismo e Ilustración», en Amorós, Celia y De MIGUEL, Ana (Eds.): Op.cit., pp. 99-100.

89. Balaguer, María Luisa: Op.cit., p 29.

90. Wollstonecraft, Mary: Vindicación de los Derechos de la Mujer, Madrid, Cátedra, 2000 , p. 317. Subrayado agregado.

91. MonTESQuiEu: El Espíritu de las leyes, Buenos Aires, Heliasta, 1984, p. 270. Voltaire también consideró natural la discriminación racial de las poblaciones del África y las concibió como una sociedad conformada por seres pasivos destinados a la esclavitud, al sufrimiento y como mero instrumentos de producción. Un ejemplo de los roles que se le asigna a las personas de piel oscura puede constatarse en papel del negro de Surinam relatado por dicho autor (VolTAire: Zadig o el destino. Cándido o el optimismo, Barcelona, Bosch, 1982, pp. 373-381). 
basada en la discriminación racial está asociado en su discurso crítico de la dominación de las mujeres: se les impuso el rol social de la dulzura y decoro para la realización del ciudadano varón. Además, era evidente su crítica a las similitudes de la discriminación de las poblaciones africanas y las mujeres, ambos colectivos debían producir conviviendo fuera del ámbito público para el disfrute del hombre, blanco y propietario ${ }^{92}$. Así, una vez más, el capitalismo que ya se había consagrado con las Declaraciones de Derechos del «hombre» empezó a cohabitar con la discriminación étnica y por sexo.

\subsection{Algunos fundamentos ilustrados de la discriminación por raza y sexo}

En cuanto al conocimiento científico, uno de los pilares de la Ilustración, cabe destacar algunas ideas que fueron cimentando la discriminación racial, es el caso de Linneo y Buffon quienes desarrollaron las concepciones sobre la diversidad de razas de los hombres ${ }^{93}$; este último hizo una clasificación de la población africana y consideró que ésta tenía poca inteligencia e incluso algunos podían parecer completamente estúpidos pues no podían pensar por sí mismos, que apenas tenían memoria y que el pasado les era totalmente desconocido ${ }^{94}$. Por su parte, Montesquieu y Voltaire consideraron que las diferencias de los hombres no europeos los hacía inferiores. Las teorías sobre la jerarquía de razas empaparon a la Ilustración reforzando las exclusiones de las personas no blancas, ni europeas. Por su parte, Hume tomando como base el evolucionismo organicista, afirmó que, entre los pueblos del mundo, sólo la especie africana no había alcanzado un grado civilizatorio que mereciese tal nombre, concluyendo que la naturaleza negra era, como el resto de las especies humanas, inferior la de los blancos. También elaboró una serie de prejuicios sobre la base del evolucionismo respecto de los judíos y armenios del Este ${ }^{95}$. Además Kant siguiendo las teorías de Blumenbach y basando sus

92. Cabe destacar también la crítica a la Ilustración discriminadora que realizó Olympe de Gouges con su Declaración de los Derechos de la Mujer y de la Ciudadana. Este documento es uno de los precedentes más importantes de la positivación de los derechos fundamentales puesto que en ella ya se plantea la concepción política de igualdad real. La obra de De Gouges también se ocupó de la necesidad de la erradicación de la discriminación racial. En su obra «La esclavitud de los negros» criticó esta particular forma de explotación y opresión (PULEO, Alicia H. (ed.): La ilustración olvidada. La polémica de los sexos en el siglo XVIII, Madrid, Antrhropos, 1993, pp. 153 y ss.).

93. García Martínez, Alfonso y Bello Reguera, Eduardo: La idea de «raza» en su historia. Textos fundamentales (siglos XVIII y XIX), Murcia, Servicio de Publicaciones de la Universidad de Murcia, 2007, pp. 31-32.

94. Ibíd., p. 37.

95. Ver su ensayo «De los caracteres nacionales», en HumE, David: Tratado de la Naturaleza Humana. Buenos Aires, Orbis, 1984. 
generalizaciones en los relatos de viajeros, que eran, a menudo, inconstrastables, llegó a describir las formas de ser de la gente según su nacionalidad y sobre las características biológicas, aseveró que los negros de África carecen por naturaleza de una sensibilidad que se eleva por encima de lo insignificante ${ }^{96}$. Apuntó que Hume lo había desafiado para que le presentase un negro que haya mostrado talento, y aseguró «que entre los cientos de millares de negros transportados a tierras extrañas, y aunque muchos de ellos hayan obtenido su libertad, no se ha encontrado uno solo que haya imaginado algo grande en el arte, en la ciencia o en cualquiera otra cualidad honorable, mientras que entre los blancos se presenta frecuentemente el caso de los que, por sus condiciones superiores, se levantan de un estado humilde y conquistan un reputación ventajosa ${ }^{97}$.

Kant también fundamentó sobre la discriminación por sexo considerando que las mujeres no podían tener una capacidad intelectual igual la de los hombres porque ése no era su rol sino el de ser bellas y delicadas, es decir, débiles por naturaleza. En su Capítulo III, «Sobre la diferencia entre lo sublime y lo bello en la relación recíproca de ambos sexos ${ }^{98}$, le impone un rol a las mujeres similar al del pensamiento roussoniano: les niega su capacidad de razonar manifestando su desprecio a aquellas mujeres que se atrevían a reivindicar la igualdad en ese acto de salir de la minoría de edad mediante la adquisición del conocimiento. Afirmó con rotundidad: «A una mujer con la cabeza llena de griego, como la señora Dacier, o que sostiene sobre mecánica discusiones fundamentales, como la marquesa de Chatelet, parece que no le hace falta más que una buena barba $»^{99}$; así, se fue construyendo la separación entre belleza y cerebro para las mujeres que no es más que una «separación drástica y una frontera artificial» ${ }^{100}$. Al respecto, desde la visión oriental de Mernissi, las mujeres en la Europa de Kant se enfrentan a la elección más terrible: escoger entre la belleza y la inteligencia y considera que ello es tan cruel como la amenaza de los fundamentalistas: o llevas la cara cubierta y así vas segura, o muestras tu rostro y sufres sus agresiones. «Una mujer que se atreva a ser inteligente recibe su castigo en el acto: se la tacha de fea» ${ }^{101}$, con lo cual, sobre la base de

96. García Martínez, Alfonso y Bello Reguera, Eduardo: Op.cit., p. 73.

97. Ibídem.

98. KANT: Lo bello y lo sublime. La paz perpetua, Madrid, Espasa, 1979, pp. 43-64. Ver también: KANT, Immanuel: Lo bello y lo sublime: ensayo de estética y moral, <http:// www.cervantesvirtual.com/servlet/SirveObras/80248352278681151532279/index. htm>, consultado el 4-09-2008.

99. Ibídem.

100. Mernissi, Fatema: El Harén en Occidente, Madrid, Espasa, 2006, p. 106.

101. Ibíd, p. 107.

Feminismo/s 12, diciembre 2008, pp. 271-298 
prejuicios si una mujer es bella, se le prejuzga y se pone en cuestión el valor académico de su producción científica puesto que en el mundo occidental, la belleza juega un papel importante en la discriminación de las mujeres ${ }^{102}$. Mernissi afirma que «el tono del libro de Kant es tan tajante como el estilo de un imán musulmán» ${ }^{103}$. La autora ejercita aquí la interpelación intercultural desde la perspectiva de género y muestra cómo las diferentes culturas tienen un punto de coincidencia, esto es, un consenso evidente incluso entre culturas enfrentadas cuando se trata de la discriminación por sexo.

\section{Conclusiones}

La discriminación por sexo y raza son barreras artificiales que se han plasmado en el Derecho para mantener las relaciones de dominación; ambas has convivido y conviven con todos los modos de producción. El Derecho y, en concreto, el derecho constitucional no ha tomado en cuenta estas formas de discriminación estructural, ni mucho menos las ideas que al respecto tuvieron y tienen los grupos discriminados. Ante la triunfante igualdad formal defectuosa, son pocas las reivindicaciones de los grupos de personas marginadas que han sido incorporadas como una necesidad primordial dentro de ámbito jurídico y si éstas algunas veces aparecen positivadas no siempre suelen alcanzar eficacia jurídica, precisamente porque toda la estructura jurídico-política

102. Mernissi ofrece datos estadísticos del dominio masculino sobre las mujeres mediante la poderosa industria de la belleza de Occidente que se encuentra bajo el poder masculino y cuyos cánones se establecen desde la visión androcéntrica. Enfatiza cómo sin respeto al pluralismo, ni acuerdo alguno, en las democracias occidentales, los parámetros de la estética femenina son autoritarios reforzándose así la teoría kantiana del siglo XVIII. Además explica cómo esta teoría de la belleza de Kant es un valor actual en el espacio público, especialmente en el ámbito laboral. La autora también resalta la crítica que hace Bourdieu en este sentido. Ibid., pp. 239-251. El citado autor afirma que la situación de dominación en la que se encuentran el resultado de una construcción social «naturalizada» que afecta a la totalidad de su cuerpo. Así, actualmente, las mujeres están obligadas a interiorizar el arte de vivir femenino, el buen comportamiento (el decoro roussoniano), aprender a vestir y llevar las diferentes piezas de ropas correspondientes a sus diferentes estados sucesivos: niña, doncella, esposa y madre de familia. Para Bourdieu esta socialización es una especie de confinamiento simbólico que queda asegurado prácticamente por su vestimenta condicionándoles su movimiento y su libertad (Bourdieu, Pierre: La dominación masculina. Barcelona, Anagrama, 2000, pp. 37-45). En efecto, sobre la base de la industria de la moda y belleza femenina sustentada en la visión masculina el mundo occidental ejerce una dominación sobre las mujeres siguiendo las pautas sentadas por los ilustrados como Rousseau, Kant, Voltaire (cuando este último refiere la importancia de la belleza y fealdad de las mujeres relatando la vida de Cunegunda) (VOLTAIRE: Op. cit., pp. 287303 y 467-473).

103. MERNISSI, Fatema: Op. cit., p. 107.

Feminismo/s 12, diciembre 2008, pp. 271-298 
sigue conservando el lastre de estos dos tipos de discriminación histórica que, en muchos aspectos, son similares. De ahí la necesidad de aplicar lo que se está avanzando en la erradicación de la discriminación por sexo en la problemática de la discriminación racial. Las bases que ha sentado la teoría feminista para su erradicación son importantes, partiendo de la propuesta de la erradicación del prejuicio y especialmente del prejuicio jurídico dominante, íntimamente vinculado a la tradición jurídica ${ }^{104}$. La crítica a los prejuicios que forman parte del contenido del Derecho viene siendo desarrollada por la teoría feminista cuyas aportaciones al derecho constitucional europeo y español actual son trascendentales; y, estas aportaciones tienen un punto de partida: la crítica elaborada a los defectos de la Constitución y constitucionalismo que sólo facilitó la liberación política a un grupo reducido de personas puesto que, ocultó dos formas de discriminación histórica, una que afecta a la mitad de la humanidad: por sexo y, la otra, por raza, que se reinventa, muchas veces, sobre la base de la primera.

104. Posada formula sus apreciaciones críticas sobre la tradición jurídica y el prejuicio jurídico cuando se trata de la discriminación por sexo (POSADA, Adolfo: Op. cit., p. 272). 